\title{
Research on the Marketing Strategy of Hengyuanxiang Brand Reshaping
}

\author{
Kangyi Du, Hongshan Zhao \\ Beijing Institute of Fashion Technology, Business School, Beijing, China
}

\section{Email address:}

15652496817@163.com (Kangyi Du), sxyzhs@ abift.edu.cn (Hongshan Zhao)

\section{To cite this article:}

Kangyi Du, Hongshan Zhao. Research on the Marketing Strategy of Hengyuanxiang Brand Reshaping. Science Innovation. Vol. 7, No. 1, 2019, pp. 31-36. doi: 10.11648/j.si.20190701.17

Received: February 12, 2019; Accepted: April 18, 2019; Published: April 28, 2019

\begin{abstract}
Chinese time-honored brands, with their rich cultural heritage, are the founders of Chinese brands and have made important contributions to China's economic development. With the development of the times, the blend of Chinese and Western culture and commerce, many domestic young fashion brands have gradually developed and matured, and foreign high-end brands have quietly entered the Chinese market, controlling the consumer psychology of Chinese consumers with their characteristics. Therefore, how to maintain the vitality of the old brand in the complicated market, to obtain high customer loyalty and to attract the attention of the new generation is still a question worth pondering. This paper will take Hengyuanxiang, one of the representatives of China's old brands, as an example, and discuss the old Brand remodeling marketing strategy in depth.
\end{abstract}

Keywords: Old Brand, Brand Remodeling, Hengyuanxiang, Marketing Strategy

\section{恒源祥老字号品牌重塑营销策略研究}

\author{
杜康伊, 赵洪珊 \\ 北京服装学院商学院, 北京, 中国 \\ 邮箱 \\ 15652496817@163.com（杜康伊），sxyzhs@bift.edu.cn（赵洪珊）
}

摘要: 中国老字号品牌具有浓厚的文化底蕴, 是中国品牌的奠基者, 为中国经济发展贡献了重要力量。随着时代的进 步发展, 中西文化、商业交融, 众多国内年轻时尚品牌逐渐发展成熟, 国外高端品牌也悄然进入中国市场, 以其特色 掌控了中国消费者的消费心理。所以, 老字号品牌如何在纷繁复杂的市场中仍保持活力, 取得较高的顾客忠诚度并不 断吸引新生代的关注, 仍是一个值得深思的问题。本文将以中国老字号品牌代表之一——恒源祥为例, 深入探讨老字 号品牌重塑营销策略。

关键字: 老字号, 品牌重塑, 恒源祥, 营销策略

\section{1. 引言}

老字号品牌是中国优秀商业文化的代表,具有浓厚的 文化底蕴及很强的文化价值、经济价值和历史价值。许多
中国传统老字号品牌如全聚德、红都、瑞蚗祥、恒源祥等, 在中国老百姓特别是老一代人们心中仍占据着重要的地 位。老字号品牌的发展和诞生,汇集了几代民族企业家的 智慧和艰辛, 其历史大多可以追溯到两个世纪之前。然而, 就目前各行各业的老字号品牌经营与发展情况来看, 大多 
数老字号已失去活力,其品牌效应力在消费者心理急剧下 降,顾客忠诚度不高, 新生消费者群体较少, 且部分老字号 在历史长河中已消失殆尽。据有效数据的统计, 截至到目 前已有将近 $70 \%$ 的老字号品牌退出了市场,还有 $20 \%$ 的老 字号品牌勉强维持惨淡经营,剩下仅有的 $10 \%$ 的老字号品 牌一直可以维持一定的规模, 而且发展良好, 并产生了较好 的经济效益。虽然还有 $10 \%$ 老字号保持活力,但这 $10 \%$ 的老 字号品牌也依然面临着种种威胁。

白玉苓 [1]（2018）指出品牌重塑是品牌的再塑造, 一 般指企业为修正或重新确定品牌定位、建立新的品牌形象 而发生的活动及过程。重新审视老字号原有的品牌形象, 激发老字号活力, 重新对老字号进行品牌定位及品牌重塑 是非常有必要的。季少融[2]（2017）认为由于受国内外经 济大环境的影响, “老字号”品牌的衰败现象尤为明显, 并 基于品牌视觉形象, 对老字号品牌活化、老字号品牌形象 的提升作了研究。老字号品牌形象的提升对老字号品牌重 塑有着重要的战略意义。从近几年关于老字号品牌重塑的 研究文献来看, 老字号品牌重塑属“当务之急”, 本文研究 迫在眉睫。

恒源祥公司在快速发展的品牌竞争时代,也经历了最 初几十年的蓬勃发展,但近几年增幅逐渐减缓。要想扩大 品牌规模、提升增长速度,恒源祥所面临的挑战不仅仅限 于来自于竞争对手的压力,还有自身品牌重塑、品牌营销 策略等一系列的问题。如何进行品牌重塑,选择适合的营 销策略对品牌进行重塑活化对恒源祥来说仍是一个亟待 解决的问题。

本文研究视的角将会从老字号品牌的重塑营销策略 入手, 运用到了品牌活化理论与恒源祥的营销策略结合起 来,探索适合发展的品牌重塑的营销策略。

\section{2. 老字号品牌定义及现状}

\section{1. 老字号品牌定义}

老字号品牌是历经多年历史风霜遗留下来的瑰宝,在 我国商业文化中占据着重要地位。有学者曾将老字号品牌 分为三大类 [3]:历史悠久的老店铺;具有传统地方特色并经 营地方特产的品牌和影响着当地人们世世代代生活的老 招牌。2005年6月,中国商业联合会开发一个新的“中国老字 号认定规范”,历史悠久的定义是:有着悠久的历史,随着一 代又一代的产品,技术或服务,具有鲜明的中国传统文化背 景和深厚的文化底蕴,有广泛的社会认同,形成良好信誉的 品牌。

\section{2. 老字号品牌现状}

随着科技的发展和时代的进步,越来越多的新兴品牌 和国外品牌逐渐进入大众视野并占据新一代消费群体的 消费市场。老字号逐渐退出经济舞台, 延续千年的老字号 会面临种种绝境。其固有的体制老化, 还是品牌价值链断 裂、经营方式陈旧、营销策略死板都会让一个饱经风霜的 老字号品牌在新时代的翻云覆雨中一跉不振。如何让现存 老字号品牌重新占领市场, 赢得消费者关注, 增添品牌活力 是老字号品牌现阶段面临的一大难题。

\section{3. 老字号品牌老化的原因}

\section{1. 国外学者关于老字号品牌老化的观点}

国外也有属于自己的老字号品牌,它们存在的问题与 国内老字号品牌基本相同。国外学者在经过一系列研究之 后寻找到了国外老字号品牌老化的原因所在, 激活品牌特 征的策略。其中,Lehu[3]（2004）提出了老字号品牌老化 的三个原因并提出解决方案。他认为老字号品牌失去活力 主要是因为:(1)企业所提供的的产品和服务存在问题:(1)产 品调研和开发滞后; 品牌分类问题;创新速度慢; 专利的生 产过程减少;旧产品或服务失去竞争力;技术落后;生产方 法达不到现行标准的要求;款式、设计和颜色过时;过时的 消费者满意度承诺。(2)来自于目标市场的问题: (1)消费者 忠诚度的降低; 消费者数量的减少;消费者的平均年龄较大; 品牌不被年轻消费者所知道的;由于不符合消费者需求而 导致新产品推广失败;目标市场没有更新换代。(3)来自品 牌营销的问题:(1)随着时间的推移, 营销宣传预算减少;(2) 传播创造力减弱;(3)包装过时;(4)品牌提及率降低;(5)媒体 计划缺乏针对性;(6)传播内容过时;(7)频繁更换广告代理, 导致核心信息模糊;(8)代言人形象“老化”或适应性差;(9)忽 略了时尚因素, 而被竞争对手巧加利用。

\section{2. 我国老字号品牌老化的原因}

国外老字号品牌衰落的原因, 对中国老字号品牌的老 化探究其原因有一定借鉴意义。但我国老字号品牌又有其 特殊性, 不能一并而论, 具体归纳我国老字号品牌老化的原 因有以下几点:

表1 我国老字号品牌老化的原因。

\begin{tabular}{|c|c|}
\hline & 过时的顾客满意承诺 \\
\hline & 过时的市场调研和产品开发 \\
\hline 产品结构老化, & 创新缓慢、专利数量减少 \\
\hline 客户资源流失 & 产品技术更新缓慢、工艺落后 \\
\hline & 不具有“时尚”特征 \\
\hline & 品牌分类混杂 \\
\hline & 生产周期过长, 资金周转不开 \\
\hline 企业负担沉重, & 雇员老龄化、文化水平不高 \\
\hline 发展后劲不足 & 企业制度旧化、无法吸引人才 \\
\hline & 国企弊端、内部机制死板、骨干流失 \\
\hline & 不进行市场细分, 无法引起消费者共鸣 \\
\hline 营销观念落后， & 营销传播预算逐年减少 \\
\hline 品牌传播乏力 & $\begin{array}{l}\text { 频换更换广告代理商, 导致品牌核心信息模糊 } \\
\text { 媒体方案旧化, 不注重运用新媒体技术 }\end{array}$ \\
\hline 商标保护不够， & 不注重商标权保护，打假力度较弱 \\
\hline 假冒产品泛滥 & 品牌形象保护不够 \\
\hline 咅口质昌沮坡 & 国外品牌进行商标抢注 \\
\hline 产品页重滑坡, & 性价比不高 \\
\hline 企业信誉丧失 & 以次充好, 以假乱真 \\
\hline 目标市场较小, & 目标市场长期不更新, 消费者数量减少 \\
\hline 消费群体模糊 & $\begin{array}{l}\text { 消费者年龄老龄化, 新生代消费群体不认可品牌价 } \\
\text { 值 }\end{array}$ \\
\hline
\end{tabular}

\section{4. 品牌重塑相关理论}

鉴于老字号品牌老化现象严重, 国内外学者针对此问 题提出了一系列振兴老字号品牌, 促使品牌重塑理论。所 
谓品牌重塑, 简言之, 就是通过“包装”使资产再生, 品牌 形象重塑从而挽救老字号品牌在消费者心里的品牌定位。

\section{1. 品牌重塑原因}

（1）当时代环境发生变化的时候, 由于品牌和产品 对环境依赖程度较高, 品牌所依赖的根基就会产生动摇, 品牌形象有损, 这时就需要进行品牌重塑。

（2）如同产品一样，品牌也有自己的生命周期，不 可避免的也要经历成长、成熟、衰败这一系列过程。当品 牌进入成熟期, 为了避免品牌走向衰败, 要不断注入新鲜 活力, 保证品牌年轻化。

（3）新生品牌所带动的新产品推陈出新, 抢在时代 发展脚步之前, 文化环境越来越变化多端是品牌重塑的一 个重要原因。老字号品牌保持吸引力为其一种营销策略, 凭借消费者对老字号品牌的信任和原有保持的较高的忠 诚度从而获得优势。

\section{2. 品牌重塑的条件}

品牌的重塑可以给品牌带来新的活力, 给消费带来者 耳目一新的感觉。但不是所有的品牌都可以重塑,重新占 据市场和赢得消费者的信任。国内外学者提出品牌重塑应 具备以下条件[3]:

(1) 品牌媒体宣传与促销明显低于竞争对手或低于行 业平均水平;

（2）品牌服务或产品价格处于竞争的中间地位。如果服 务或产品价格高于竞争对手,也要降低价格,那么品 牌就无法重建;

(3) 品牌有着悠久的历史, 有着巨大的品牌传承,也能在 某些方面引起消费者的注意;

(4) 如果品牌的价值不是很好的话, 则产品销量必须很 大,而且知名度比较高;

（5）与竞争对手相比,品牌在产品、沟通、包装和形式 上具有不同的竞争优势;

（6）品牌的核心价值在市场中占有很重要的地位, 它可 以通过重塑与当前消费者的利益相一致。

从以上条件来看,对老字号品牌要不要重塑,哪些可以 进行重塑, 不能盲目进行, 应先进行品牌评估, 再进行决策。

\section{3. 品牌重塑的决策方法}

进行品牌重塑需要多方的考察与协作, 有效的品牌重 塑对振兴中国老字号发展具有深远意义。通过借鉴西方理 论, 针对中国老字号品牌独有的特点, 可总结出进行品牌 重塑的一些思路与方法:

（1）技术创新与新产品开发。在传承企业文化、继承支 柱产品的前提下, 积极改进生产工艺, 引进先进技 术, 提升创新能力, 进行市场细分, 重新进行品牌 分类, 引入带有“时尚感”的新型产品, 重新建立品 牌与消费者的密切联系, 拥有更大的市场空间, 抢 占市场份额, 保留顾客忠诚度同时开拓更广阔的目 标市场，稳固消费者心目中的品牌形象。

（2）走复古路线,打怀旧牌,用情感诉求去追溯消费者。 大部分的消费者对过去的经历或东西一般都有着
很深的感情, 尤其是传统的老一辈消费者, 很多人在 他们年轻的时候都使用过一些老字号的产品,这些 产品甚至伴随着它们的成长。旧品牌往往能让消费 者回忆起童年,更容易与他们产生共鸣。如果通过 营销唤醒消费者的记忆, 就可以建立老品牌与特定 群体之间的关系。同时开发品牌故事,引入新媒体 将品牌故事进行视频化呈现在大众面前, 更大程度 的加深了消费者与品牌的感情联络与密切互动。

（3）进行品牌延伸。老字号品牌不应该局限于某一行业 或某一种类。现在大型集团都跨行业扩大市场, 多 方法全面稳固品牌形象, 培养品牌影响力。老字号 品牌可通过品牌延伸,为老品牌注入新鲜的血液,使 老品牌重新活跃在大众的视野中。但是, 凡事都有 两面性, 品牌延伸也是一把双刃剑。例如:使品牌个 性模糊, 影响品牌个性, 甚至影响品牌内部关系等 等。因此, 在进行品牌延伸的时候,一定要秉持谨慎 审视的原则, 强化新老品牌之间的联系, 不断提升品 牌内部兼容能力, 重视质量监控, 在进行品牌延伸之 前进行全面规划与掌控。

(4) 加强品牌的宣传力度, 重视品牌的营销, 科学的实施品 牌发展战略。当前,大多数老字号品牌都处于一种休 眠的状态, 导致老字号品牌的传播停滞不前, 品牌的号 召力没有得到充分发挥, 品牌潜能没有被激发。随着 新媒体的广泛应用, 人们接受能力的逐步提升, 老字号 品牌不能继续使用固有的传统传播方式。老字号品牌 除了依靠传统的口碑式宣传外,还应该重视广告、公 关、社会活动、网络等渠道来传播品牌, 扩大其市场 和社会声誉。有效的品牌传播可以促进产品进入目标 市场, 有助于新产品的开发。吸引新的消费群体,从而 扩大产品销售量,顺利进行品牌营销。

\section{5. 恒源祥品牌营销现状}

恒源祥作为中华老字号品牌之一, 其渊源的历史和其 刻在骨子里的品牌文化无时无刻不影响着消费者。但老字 号品牌活力日渐丧失, 恒源祥也难独善其身。老字号品牌 一直在探索品牌重塑之路, 恒源祥也紧跟脚步, 让自己在 这复杂多变的市场环境中仍能保持活力, 充实品牌力量, 稳固品牌形象。在老字号品牌重塑方面, 针对恒源祥的具 体情况, 着重从恒源祥的营销策略入手, 多方面分析其营 销现状, 探索更能为恒源祥品牌注入新鲜活力、传播品牌 形象的营销策略。

\section{1. 恒源祥品牌营销渠道现状}

对于一个品牌来说, 品牌营销渠道对提升产品销量、 抢占市场份额、赢得消费者喜好起着至关重要的作用。 尤其对老字号品牌而言, 大多数的老字号品牌曾经都是 靠着口口相传而闻名, 没有运用媒体进行广告宣传和社 会大事件进行热度提升。随着新媒体的快速发展, 营销 传播已不能仅仅靠着大众的口头传播, 更应运营新媒体 进行线上线下传播, 使品牌和产品同时进入大众视野, 提高其知名度。 


\subsection{1. 线下渠道模式}

恒源祥品牌渠道成员分为零售商和分销商。零售商与 经销商、公司之间的合作需要签订公司特许权合同,公司
在许可证签发后可以进行实质性操作。一般来说,分销商 是根据区域分工建立的,零售商一般是由经销商发展的。 有些经销商也可以同时建立直营店。

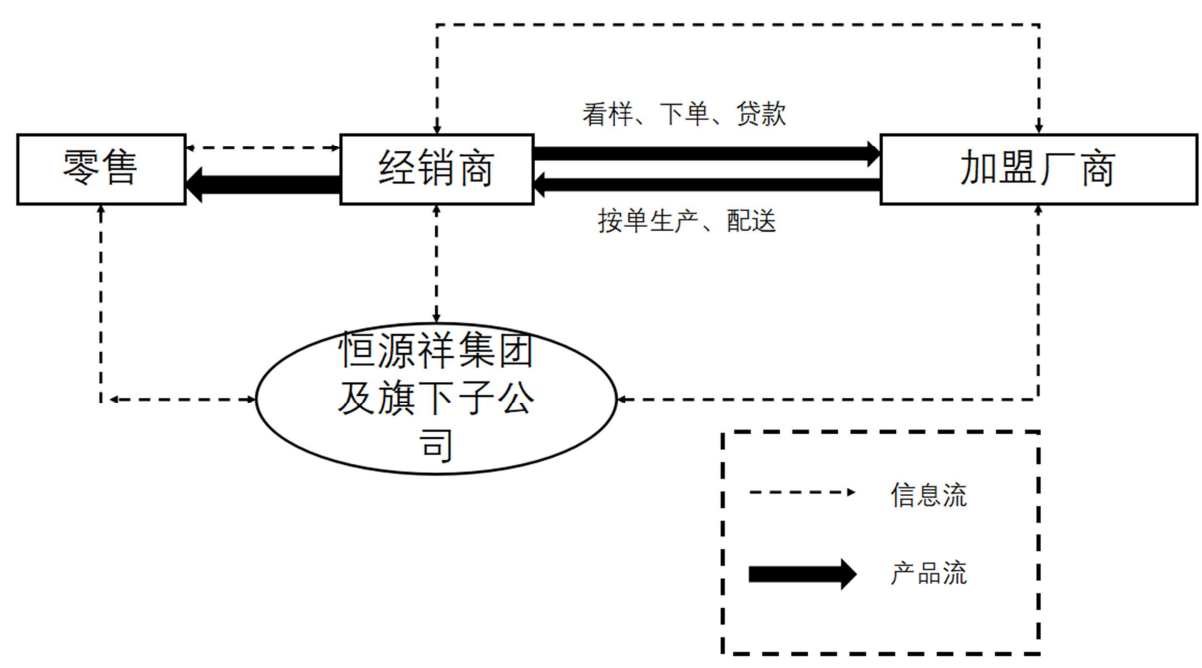

图1 恒源祥集团线下渠道模式图。

\subsection{2. 线上渠道模式}

老字号品牌最大的弊端是不擅长利用新媒体进行品 牌传播。而能一直屹立于历史长河的为数不多的老字号品 牌, 已慢慢开始接受新媒体传播带来的影响力。恒源祥作 为发展悠久的老字号品牌之一, 也在不断整合自己的传播 渠道与宣传模式, 除了传统的线下渠道模式外, 也积极响 应时代号召, 开通了线上渠道模式。

恒源祥线上渠道模式一直在改进, 整个旗舰店内容较 为丰富, 应季产品和打折促销并具, 首页广告设计也应景, 其中，在商品品类中，恒源祥旗舰店同时销售围巾系列、 羊线衫系列和内衣系列。其中围巾系列商品的月销量明显 高于其他品类，一款售价仅为 99 人民币的女士羊毛围巾月 销量超过四位数。但除了围巾系列, 羊线衫和内衣系列月 销量仅仅只有两位数, 个别产品甚至出现 0 销量。可见, 虽然恒源祥积极打通线上渠道模式，但网络旗舰店的销售 额也不容乐观。

\section{2. 恒源祥品牌宣传现状}

公司向消费者以及渠道成员提供信息和品牌推广, 主 要途径是通过大型体育营销活动、国家慈善活动、媒体广 告和软内部出版物等途径实现。在硬广告和大型营销及公 关活动中,公司主要总公司的广告宣传策略。整个集团包 括各子公司的媒体广告投放,基本上由本集团广告部安 排。集团还计划进行大规模的营销活动。附属公司需要做 的是利用集团现有资源参与或配合执行。

\section{6. 恒源祥品牌存在的问题}

\section{1. 产品与价格存在问题}

虽然公司品牌及旗下子公司产品仍然采用的是自己不 生产、不设计模式, 但由于总公司处在主导地位, 对各加盟
工厂仍然有很强的整合、引导能力。目前, 老字号品牌的产 品的同质化现象严重, 缺乏自主创新能力, 产品附加值低, 产品结构不合理, 不能表现品牌的差异性; 同时各品类的产 品市场需求已从单一的以实用性为主朝着艺术性、个性化、 多功能方向发展, 消费者更加追求时代感、文化内涵。

\section{2. 渠道组合存在问题}

集团目前的渠道结构主要为单一的经销商、零售商组 成的传统分销结构, 局限性很大。而且虽然开通了网络旗 舰店线上渠道模式，但其销量一般。随着整个市场环境的 改变以及消费者购买行为的转变, 建议公司的渠道结构也 作适当的调整, 可以考虑引入电视购物、呼叫中心和网络 销售相结合的形式，实现传统渠道与“空中渠道”互补的两 条腿走路的渠道组合, 并且不断增强线上渠道模式的宣传 力度, 积极参与到各大电商平台的网络狂欢节, 依靠促销 来带动部分产品的销量和减轻库存压力。

\section{3. 品牌宣传存在问题}

恒源祥虽一直在紧跟时代脚步, 不断采用新媒体宣传 方式和借用公众大事件进入公众视野, 但其营销手段过于 传统、老旧, 现代人们的生活方式正发生着翻天覆地的变 化，人们已很少接触传统媒体如电视、电台等，中国网民 正在成为一个新型群体并日益壮大, 人人有微信人人刷微 博, 而恒源祥却没有巧妙的利用社交软件及其他新媒体渠 道进行宣传, 在新媒体时代, 应将更多的注意力集中在新 媒体营销方面。

\section{7. 恒源祥品牌重塑营销策略}

\section{1. 更新生产技术, 坚持战略定价}

恒源祥作为老字号品牌, 与众多老字号品牌一样, 都 存在一个致命的问题, 就是生产技术创新能力不高、产品 
包装老旧、产品设计缺少“时尚感”。作为一个百年老字号, 恒源祥必须不断引入先进的生产技术, 提升创新能力, 增 加专利数量, 注意产权保护。

恒源祥品牌为知名品牌, 且品牌形象一直比较稳定, 所以品牌战略定价策略更能让公司明确方向, 而不是跟着 竞品走或者简单的根据成本定价。这个策略主要以自身品 牌定位及目标市场的需求而制定价格标准。建议针对不同 系列的产品, 根据其定位以及目标消费群体的购买心态, 制定不同的价格水平。

\section{2. 优化渠道组合, 开通“电子商务+电视购物+呼叫中心” 模式}

在互联网高速发展的新时代, 只有顺应时代潮流, 才 能赢得消费者内心, 拥有较高的消费者忠诚度。如今的消 费者购买行为已逐渐发生改变, 在传统观念中, 消费者的 购买行为分为几个步骤: 注意——发生兴趣——产生购买 欲望一记忆一最后行动。而当代的消费者行为已经转 变为:注意——发生兴趣——搜集相关信息——行动— 分享。如图2、3:
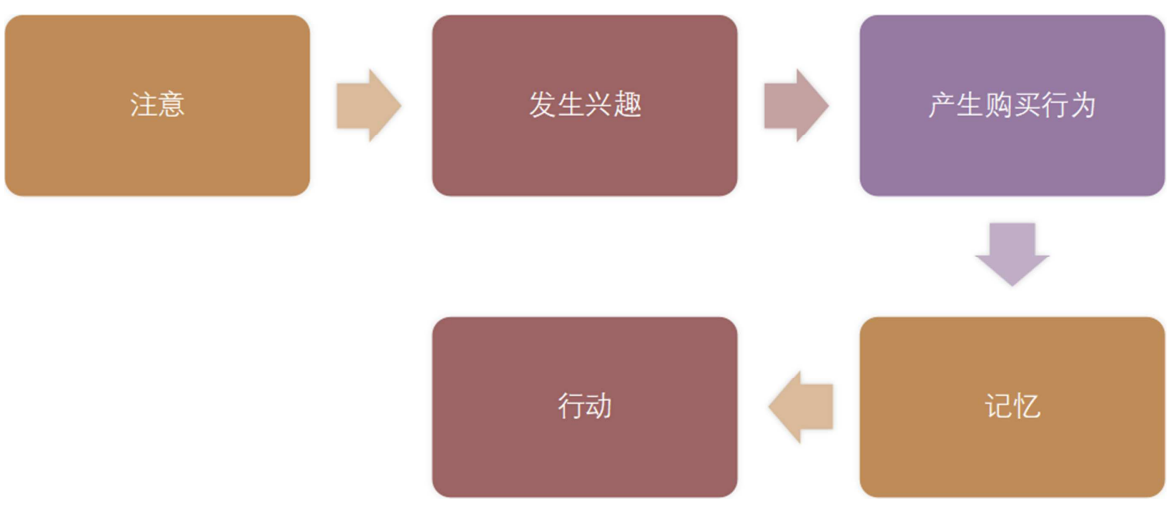

图2 传统消费者购买行为。
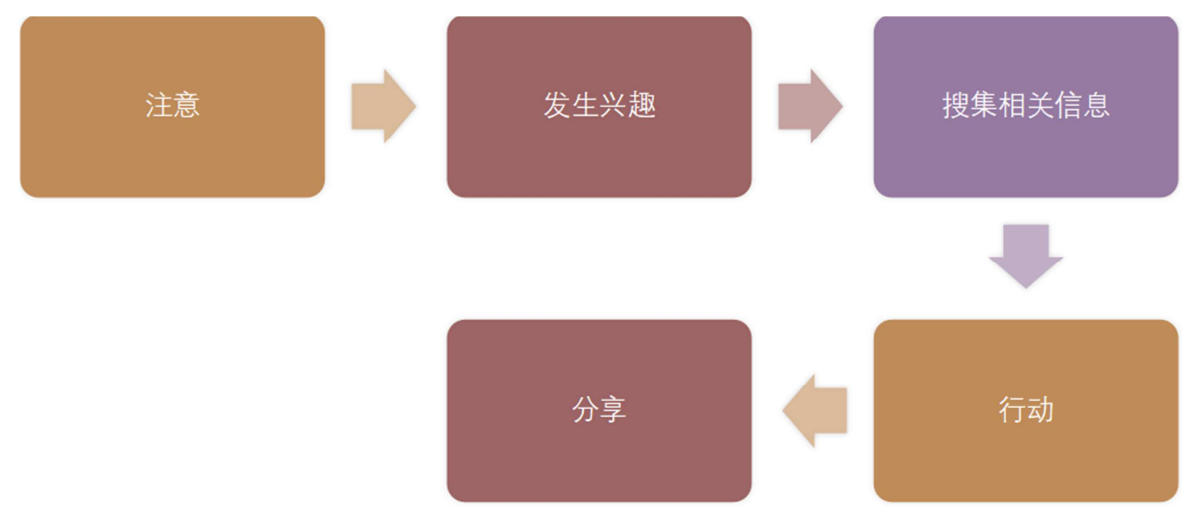

图3 当代消费者购买行为。

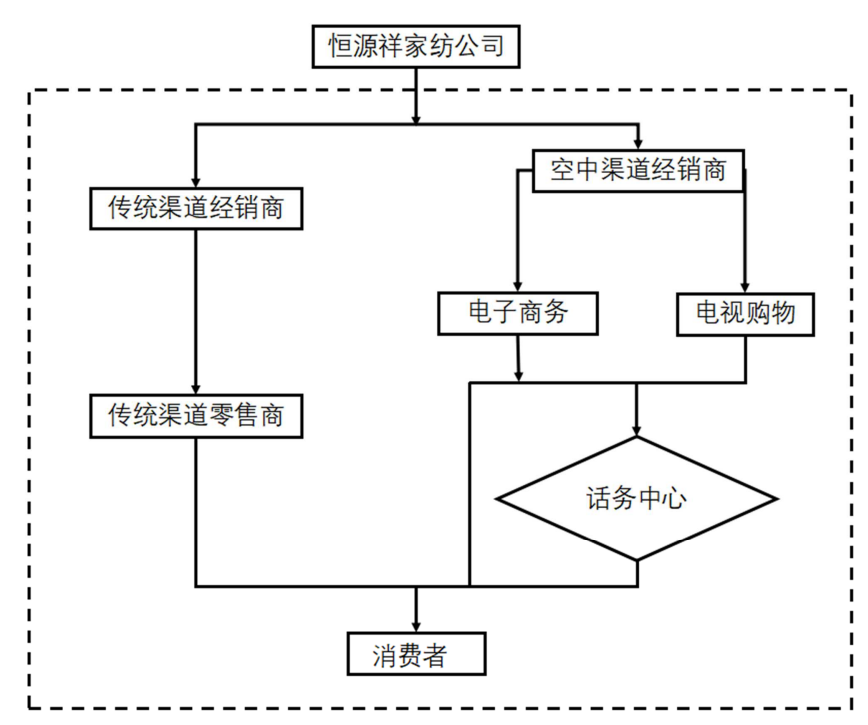

图4 恒源祥线上线下“电子商务+电视购物+呼叫中心”模式图。
尤其是在网络普及以后, 利用互联网的便利, 更加剧 了消费者行为的这一转变。越来越多的人们开始利用网络 购物, 利用网络搜集信息, 并利用网络将自己的体验和心 得与其它人分享。网络的出现也给渠道带来了巨大的变化, 渠道被视为企业的重中之重。

“电子商务+电视购物+呼叫中心”这一模式的应用对 于恒源祥公司来讲, 虽然无法自己直接销售, 但仍然可以 通过第三方的形式来实现。即选择专业的经销商, 统一电 子商务和电视购物, 两种销售方式有共用的呼叫中心和数 据系统, 总公司为其提供营销及其它支持。最重要的是通 过这样的渠道, 公司能建立庞大的消费者数据库, 对未来 品牌的发展和销售都有非常大的参考意义。

另外, 除了渠道模式的改变外,恒源祥想进行品牌重 塑,重新赢得消费者喜好和分销商的支持,也要注重渠道 终端的管理。恒源祥公司采取的是授权经营的市场拓展 方式,其最终顾客是消费者, 但直接顾客是经销商, 关键顾 客是一批销售量大、经营能力强的重要经销商。对这些 
经销商来说,他们对公司、品牌的需求是产品质量好、供 货及时、市场营销支持; 重要经销商的需求则体现在品牌 文化、员工培训、广告支持三个方面。所以在以往的服 务和管理活动中,恒源祥公司的工作重点应围绕经销商 为核心展开。

\section{3. 特色宣传, 搞活品牌}

对于任何品牌而言, 广告对其的影响都是至关重要 的。优秀的品牌在作广告时兼顾知名度和美誉度。知名 度是靠传播做出来的, 靠广告轰出来的;而美誉度则是传 播的内容, 是广告传达给消费者的内容。恒源祥的知名 度已经达到 $96.3 \%$, 她更需要美誉度, 因此在未来恒源祥 广告历程中更多的需要一些美誉度的内容。恒源祥不管 是品牌名还是发展史, 都带着浓厚的中国传统特色, 如 果能把品牌发展和国家文化紧密相连, 对企业来讲则非 常的具有竞争优势。恒源祥与生俱来的百年老字号品牌 形象, 更有利于将宣传策略与中国文化完美契合, 更能 得到广大消费者的认可。只要恒源祥品牌持之以恒, 不 断去创新, 和新媒体宣传相结合, 将中国五千年来优秀 的传统文化与品牌文化完美融合, 展示给世人, 定能取 得不同凡响的效果。

\section{8. 总结与展望}

回顾中国百年品牌, 各有其特色, 各有其魅力。老字 号品牌虽历经沧桑, 几起几落, 但是仍是中国传统商业构 成中不可缺少的一部分。老字号品牌重塑是一条艰辛而又 光荣的道路, 老字号经久不衰的品牌形象需要随着时代的 变化而永驻世间。正确进行老字号品牌重塑, 将给广大中 华子孙带来珍贵的遗产宝藏。

在经济飞速发展、时代转变飞快的时代, 恒源祥要 想屹立于中国品牌届, 则更需要其不断进步、创新、发 展, 以迎合时代发展的需求。它所面临的挑战已并非来 自于竞争者, 而是市场环境的巨变和消费者行为的速 变。

\section{参考文献}

[1] 白玉苓. 老字号品牌重塑中的时尚化定位及策略研究 [J]. 品牌研究, 2018, 18(06):20-23。

[2] 季少融.“老字号”品牌重塑视觉形象的提升路径研究 [D]. 浙江工业大学, 2017。

[3] 彭博,昆钢令.中国传统老字号品牌激活研究 [J].现代管理科 学, 2012(3)。

[4] Lehu J. Back to life! Why brands grow old and sometimes die and what managers then do: An exploratory qualitative research put into the French context[J]. Journal of Marketing Communications, 2004, 10(2):133-152.

[5] 严芳琴. 老字号品牌活化策略的有效性研究 [D]. 华东师范 大学, 2014。

[6] 刘敏. 恒源祥家纺公司营销策略研究[D]. 复旦大学, 2009。

[7] 孙苏.构建具有强势品牌竞争力的研究 [J]. 管理视野, 2006: 94-95。

[8] 李强强. 论网络营销与传统营销渠道的冲突及对策[J]. 时代 经贸,2007(5): 23。

[9] 潘国锦. 品牌理论研究现状 [J]. 商业经济文荟, 2006(2): 37-39。

[10] 陈金叱,张锐.品牌老化的成因探析, 商场现代化, 2005 (44) :178-179。

[11]姜宁，席升阳. 老字号品牌延伸的利与弊.河南科技， 2007(12):14- 15。

[12] 康微.品牌老化及其对策.中国青年政治学院学报, 2003(5):110- 114。

[13] 冷志明.“中华老字号”品牌发展滞后原因及其对策研究. 北 京工商大学学报(社会科学版), 2004(19):55-58。

[14] 文芳.重塑百年老字号品牌形象 [J].中国纺织报，2005(4)。 